\title{
The in Vitro and in Vivo Photoreactivity of Bilirubin: I. Laser-Defined Wavelength Dependence
}

\author{
GARY R. GUTCHER, ${ }^{(43)}$ WILLIAM M. YEN, AND GERARD B. ODELL \\ Departments of Pediatrics and Physics, University of Wisconsin, Madison, Wisconsin, USA
}

\begin{abstract}
Summary
Monochromatic light was provided by a continuous wave Argon ion laser. We chose to study the in vitro effects of light at 457.9, $465.8,476.5,488.0,501.7$, and $514.5 \mathrm{~nm}$ as representative of a reasonably evenly spaced sampling across the blue-green spectrum. The in vivo experiments were conducted at 457.9, 476.5, 488.0 , and $514.5 \mathrm{~nm}$.

In vitro light at $488.0 \mathrm{~nm}$ appeared to be more effective than the others studied.

After $24 \mathrm{~h}$ of irradiance, the in vivo decline in serum bilirubin concentration produced by light at $488.0 \mathrm{~nm}$ was one-and-one-half, two, and four times as effective as light at $457.9,476.5$ and 514.5 $\mathrm{nm}$, respectively. By $48 \mathrm{~h}$ of exposure, the declines produced by light at $457.9 \mathrm{~nm}$ and $488.0 \mathrm{~nm}$ are significantly superior to that at $476.5 \mathrm{~nm}$ and $514.5 \mathrm{~nm}$, but they do not differ from one another.
\end{abstract}

The photon-induced chemical alteration of bilirubin has been demonstrated by various light sources both in vitro and in vivo. The clinical application of this phenomenon has been widely used as phototherapy in the treatment of neonatal hyperbilirubinemia. Investigations designed to delineate the effective wavelengths have employed broad spectrum light sources and have indicated that irradiance with light of wavelengths of $425-475 \mathrm{~nm}$ is maximally effective both in vitro $(2,7,8,10,13,25,31)$ and in vivo $(1,11,17$, $24,29,33,36$ ). But one study performed in vitro with a relatively narrow spectral source suggested wavelengths at $490 \mathrm{~nm}$ might also be efficacious (10). More recently, Lilien et al. (27) have performed experiments that also suggest that wavelengths of light beyond the $425-475 \mathrm{~nm}$ range are efficacious in vitro.

Radiant energies within the $400-500 \mathrm{~nm}$ range exhibit potential for inducing damage to tissues. Light from standard fluorescent lamps causes breaks in DNA strands in vitro $(3,35)$ and increases sister chromatid exchanges and other chromosomal alterations in cultured cells $(4,18,21,23,32,35,37)$. An increased frequency of sister chromatid exchange has been reported in some infants after phototherapy (12). Although we know of no reports regarding any increase in sister chromatid exchange in vivo in response to monochromatic light, the occurrence seems likely; thus, the widespread use of phototherapy has generated concern regarding the potential for long-term mutagenic and carcinogenic effects. Inasmuch as most published data suggest that the offending wavelengths are principally in the ultraviolet range, some recent work has implicated light of wavelengths exceeding $300 \mathrm{~nm}(9)$ and, indeed, some alterations appear to occur maximally in response to wavelengths of light between $420-500 \mathrm{~nm}$ (35). Although the magnitude of these latter risks has not been quantitated as they may relate to the clinical setting, it seems desirable to more precisely define the most efficacious wavelengths for the photoalteration of bilirubin that results in its enhanced excretion. This is particularly needed in the design of future phototherapy instruments to be used in the management of neonatal hyperbilirubi- nemia. Preliminary portions of these data have been previously published $(14,15)$.

\section{MATERIALS AND METHODS}

Light source. Monochromatic light was provided by a continuous wave Argon ion laser (Model 165-008, Spectra-Physics, Mountain View, CA), which is capable of emitting light at precisely $457.9,465.8,472.7,476.5,488.0,496.5,501.7$, and $514.5 \mathrm{~nm}$. We chose to study the in vitro effects of light at 457.9, 465.8, 476.5, $488.0,501.7$, and $514.5 \mathrm{~nm}$ as representative of a reasonably evenly spaced sampling across the blue-green spectrum. The in vivo experiments were conducted at $457.9,476.5,488.0$, and $514.5 \mathrm{~nm}$. These wavelengths were selected on the basis of the data obtained in vitro and the power output limitations of the laser.

The laser was tuned to $\mathrm{TM}_{00}$ mode. For the in vitro studies the nominal 2-mm diameter beam was expanded to $5-\mathrm{cm}$ diameter and provided essentially uniform energy fluence across the small cuvette face. A series of mirrors and lenses was used to expand the laser beam to a $15-\mathrm{cm}$ diameter "target" for the in vivo studies. In the latter the irradiance was gaussian in distribution across the target and the laser and lens system were adjusted to provide 1.0 $\mathrm{mW} / \mathrm{cm}^{2}$ at the target center at the level of the animal's back. The cage diameter was restricted to insure $0.4 \mathrm{~mW} / \mathrm{cm}^{2}$ irradiance at the circumference.

For all experiments, irradiance was monitored with a laser power meter (Model 820, Newport Research Corporation, Fountain Valley, CA) and stability was assured at $\pm 2 \%$ of output.

Chemical assays. The in vitro photoalteration of bilirubin in solution was monitored both by changes in absorbance at $460 \mathrm{~nm}$ and by quantitation of the remaining diazo reactive pigment. The diazo analyses were performed by a micromodification of the Malloy-Evelyn method for total bilirubin (28). "Fractional remaining bilirubin" was expressed both as the fraction of remaining extinction at $460 \mathrm{~nm}$ and as the fraction of remaining diazoreactive material when compared to the initial or baseline amount. All fluid samples were shielded from ambient light with aluminum foil and assays were conducted under subdued lighting conditions.

Experimental design. In vitro experiments were conducted on solutions of bilirubin $\left(3.42 \times 10^{-4} \mathrm{M}\right)$ in a human albumin $(4.34$ $\left.\times 10^{-4} \mathrm{M}\right)$ phosphate buffer solution $(0.1 \mathrm{M}, \mathrm{pH}=7.4)$. The albumin-phosphate buffer solutions were prepared $24-48 \mathrm{~h}$ before each experiment. One hour before each experiment, $3.42 \times 10^{-6}$ moles bilirubin (Sigma Chemical Co., St. Louis, MO) was rapidly dissolved in $0.20 \mathrm{ml}$ of $0.1 \mathrm{~N} \mathrm{NaOH}$ and added to $9.8 \mathrm{ml}$ of the albumin-buffer solution. The solution was slowly and mechanically stirred for $30 \mathrm{~min}$ and then allowed to sit for $30 \mathrm{~min}$. To each cuvette of one millimeter lightpath, $0.20 \mathrm{ml}$ test solution was added. The cuvettes were tape-masked to permit irradiation of only that portion of the cuvette that contained solution $\left(2 \mathrm{~cm}^{2}\right)$.

In our in vitro experiments, we assumed the photochemical convention that expresses dosimetry as photon fluence (number of photons $/ \mathrm{m}^{2}$ ) rather than energy fluence (Joules $/ \mathrm{m}^{2}$ ). At each 
wavelength, the laser output was adjusted to provide an irradiance (power/unit area) such that the photon fluence rate (number of photons/unit area/unit time) was equal for all wavelengths (4.4 $\times 10^{19}$ photons $/ 2 \mathrm{~cm}^{2}$ cuvette face $/ \mathrm{min}$ ). Time then became the analog of photon fluence. Exposures were conducted for 0, 4, 8, $12,16,20$, and $24 \mathrm{~min}$.

For the in vivo experiments, we assumed the clinical convention of dosimetry that monitors irradiance or the power per unit area $\left(\mathrm{mW} / \mathrm{cm}^{2}\right)$. In all in vivo experiments, we used the congenitally jaundiced male of the Gunn rat strain 3-6 months of age, weighing $250-400 \mathrm{~g}$. The choice of animal was based on a serum bilirubin concentration of 7-12 mg/dl on two consecutive days and that these two values were within $1 \mathrm{mg} / \mathrm{dl}$ of one another. Serum bilirubin concentrations on days 3 and 4 ( 24 and $48 \mathrm{~h}$ of exposure) were used to compute the fractional decline of bilirubin concentration based on the average pre-irradiation serum bilirubin from days 1 and 2. The animal's back was shaved daily during irradiation, food and water were provided ad libitum and body weight, hematocrit, and water intake were recorded. An animal was excluded from the study if its weight changed by more than $5 \%$ during the study period or its hematocrit varied by more than $5 \%$ points during the 4-day study.

During the pre-exposure portion of the in vivo studies, the rats were housed in quarters that provided $12: 12 \mathrm{~h}$ cycled fluorescent light. During exposures to the laser, no ambient light was permitted.

\section{RESULTS}

In Vitro. Table 1 depicts the fractional remaining bilirubin for each wavelength as monitored both by the absorbance at $460 \mathrm{~nm}$ and diazoreactivity. At each wavelength, the decline in bilirubin as estimated by the diazo method is greater than the decline when monitored as O.D.460.

The decline in diazo-reactive material is best described by the exponential equation $\frac{\mathrm{N}}{\mathrm{N}_{\mathrm{o}}}=\mathrm{e}^{-\mathrm{kF}}$, where $\mathrm{N}=$ remaining diazo reactive material, $\mathrm{N}_{\mathrm{o}}=$ starting diazo reactive material, $\mathrm{F}=$ photon fluence and $\mathrm{k}$ is the proportionality constant. When fit to the data for each wavelength studied, this equation describes the decline with correlation coefficients of -0.977 to -0.997 . This is graphically depicted in Figure 1.

At $\mathrm{N} / \mathrm{N}_{\mathrm{o}}$ equals 0.370 , and $\mathrm{kF}$ equals 1.0 . The time and photon fluence necessary to achieve this level of inactivation is displayed in Table 2. In vitro, light at $488.0 \mathrm{~nm}$ appeared to be more effective than the others studied.

Table 3 displays the fractional decline in serum bilirubin con-

Table 1. In Vitro decline in bilirubin

\begin{tabular}{cccccccc}
\hline & \multicolumn{6}{c}{ Fractional remaining bilirubin as a function of } \\
Wave- & & \multicolumn{7}{c}{$\begin{array}{c}\text { exposure } \\
\text { length } \\
\text { (nm) }\end{array}$} & & Method & $1.70^{3}$ & $3.40^{3}$ & $5.10^{3}$ & $6.81^{3}$ & $8.51^{3}$ & $10.21^{3}$ \\
\hline \multirow{2}{*}{457.9} & $D^{1}$ & 0.836 & 0.718 & 0.582 & 0.545 & 0.500 & 0.436 \\
& O.D. $^{2}$ & 0.950 & 0.897 & 0.845 & 0.823 & 0.792 & 0.783 \\
465.8 & D & 0.813 & 0.738 & 0.654 & 0.579 & 0.533 & 0.495 \\
& O.D. & 0.946 & 0.919 & 0.887 & 0.882 & 0.849 & 0.824 \\
476.5 & D & 0.786 & 0.653 & 0.541 & 0.480 & & 0.378 \\
& O.D. & 0.894 & 0.904 & 0.871 & 0.831 & & 0.784 \\
488.0 & D & 0.813 & 0.659 & 0.516 & 0.429 & 0.341 & 0.308 \\
& O.D. & 0.933 & 0.893 & 0.845 & 0.807 & 0.762 & 0.753 \\
501.7 & D & 0.727 & 0.578 & 0.516 & 0.461 & 0.391 & 0.360 \\
& O.D. & 0.899 & 0.845 & 0.807 & 0.785 & 0.759 & 0.748 \\
514.5 & D & 0.897 & 0.813 & 0.738 & 0.654 & 0.636 & 0.598 \\
& O.D. & 0.956 & 0.923 & 0.903 & 0.891 & 0.887 & 0.865 \\
\hline
\end{tabular}

\footnotetext{
' $\mathrm{D}$, diazo method.

${ }^{2}$ O.D., optical density at $460 \mathrm{~nm}$.

${ }^{3}$ Photon fluence $\times 10^{20}$.
}

centration in the Gunn rat model. At $24 \mathrm{~h}$ irradiance, the in vivo decline in serum bilirubin concentration produced by light at $488.0 \mathrm{~nm}$ was one-and-one-half, two, and four times as effective as light at $457.9,476.5$, and $514.5 \mathrm{~nm}$, respectively. These differences are statistically significant for 476.5 and $514.5 \mathrm{~nm}$. By $48 \mathrm{~h}$ of exposure, the declines produced by light at $457.9 \mathrm{~nm}$ and 488.0 $\mathrm{nm}$ are significantly superior to that at $476.5 \mathrm{~nm}$ and $514.5 \mathrm{~nm}$, but they do not differ from one another.

\section{DISCUSSION}

A plot of the relative efficiency of producing a photochemical event versus the wavelength of light used defines the action spectrum of that photochemical process. Because photons must first be absorbed before they can induce a given effect, the action spectrum usually resembles the absorption spectrum of the chromophore if several experimental conditions are fulfilled. Jagger has comprehensively described these conditions (20) and they include (19): (1) similarity of the fluence-effect curves at all wavelengths, implying the same mechanism of action; (2) similar quantum yields at all wavelengths; (3) identity of the in vitro and in vivo absorption spectra of the chromophore; (4) negligible or constant absorption and scattering of light at all wavelengths within the subject system; and (5) reciprocity of time and fluence rate under the conditions studied, i.e., a given fluence produces a given effect when time and fluence rate are inversely varied.

Much of this basic photochemical data has yet to be determined for bilirubin. The difficulties encountered to date, derive principally from a relative ignorance regarding the mechanism(s) involved in the photochemical process, the identity and characteristics of the product(s), and the absence of an accurate measure of the molecular events of interest. These shortcomings have hampered our ability to achieve the conditions set forth by Jagger and, consequently, hampered the delineation of an action spectrum; however, several approximations exist $(10,25,26)$. In reviewing earlier studies, it is noteworthy that the aqueous insolubility of bilirubin has necessitated the use of a variety of unphysiologic solvent systems or has compelled investigators to use the bilirubinbinding properties of human albumin in order to obtain soluble and more stable preparations. Because most bilirubin in serum is bound to albumin, it becomes tempting to conclude that the most efficient wavelengths in vivo would be those corresponding to the extinction curve of albumin-bound bilirubin. i.e., maximal absorbance at $425-475 \mathrm{~nm}$. But at least three lines of evidence suggest that other wavelengths may be equally or even more effective. First, the data of Glauser, et al. (10) suggested that the action spectrum of bilirubin dissolved in plasma was not identical to its absorption spectrum. Maximal bilibrubin destruction was reported at $370,410,450$, and $490 \mathrm{~nm}$, though their measure of bilirubin degradation has subsequently been demonstrated to be unreliable (30). Second, the work of Vogl (42) has indicated that the superficial skin is the site of action for phototherapy. Furthermore, Kapoor et al. (22) and Broderson (5) have shown that bilirubin binds significantly to skin membranes and in this state exhibits an absorption maximum circa $490 \mathrm{~nm}$. One may postulate the existence of a membrane-bound bilirubin chromophore in vivo. Third, the preliminary findings of Lilien, et al. (27) suggest a greater efficiency of wavelengths of light beyond the $425-475 \mathrm{~nm}$ range in whole blood studies.

Our own data in vitro would appear to partially confirm the findings of Glauser; however, recent information suggests that the spectrophotometric characteristics of "dissolved" bilirubin are highly variable and that it may exist in solution as a finely dispersed colloid, as a flocculant, or as oxidation products $(6,24)$. Our bilirubin solutions were made at molar ratios of less than 1.0 with respect to albumin and in a manner designed to maximize the existence of bilirubin in the albumin-bound state. We cannot be certain of the physical state of the pigments when irradiated; thus, it is conceivable that the apparent efficiency of light at 488.0 $\mathrm{nm}$ may be an artefact imposed by the existence of bilirubin in an 


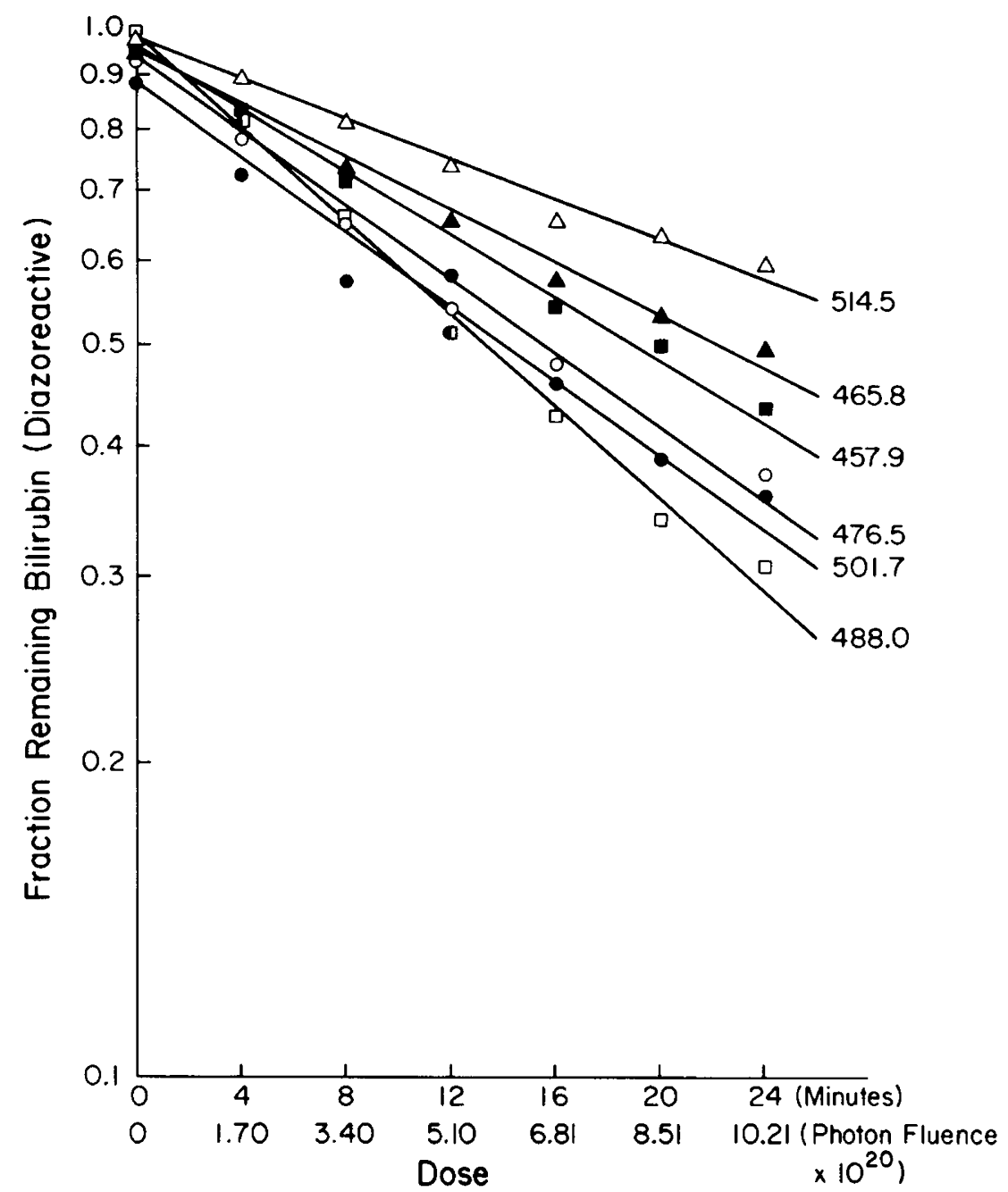

Fig. 1. In vitro decline in bilirubin (logarithmic scale) as a function of dose (min or photon fluence).

Table 2. Calculated in vitro time constants

\begin{tabular}{ccc}
\hline \multicolumn{3}{c}{ Time (number of photons) necessary to achieve } \\
& $\begin{array}{c}\mathrm{kF}=1,\left(\frac{\mathrm{N}}{\mathrm{N}_{0}}=\mathrm{e}^{-\mathrm{kF}}\right) \\
\text { Time to } \mathrm{N} / \mathrm{N}_{0}=\end{array}$ & $\begin{array}{c}\text { Photon fluence }(\times \\
\left.10^{20}\right) \text { at } \mathrm{N} / \mathrm{N}_{0}=0.370\end{array}$ \\
Wavelength $(\mathrm{nm})$ & $0.370(\mathrm{~min})$ & 11.6 \\
\hline 457.9 & 27.38 & 13.9 \\
465.8 & 32.75 & 9.8 \\
476.5 & 23.05 & 8.2 \\
488.0 & 19.23 & 9.2 \\
501.7 & 21.52 & 18.0 \\
514.5 & 41.35 & \\
\hline
\end{tabular}

altered physical state during the experiment. Subsequently demonstrable loss of diazo reactivity would then be in response to light absorbed at this longer wavelength by the artifactual physical state of the "dissolved" bilirubin. The quantitative discrepancy in estimating unreacted bilirubin by O.D.460 versus diazo positivity suggests that mixtures of photoproducts and the bilirubin itself absorb well at the monitored wavelengths of $460 \mathrm{~nm}$ and underestimates the photochemical events. On the other hand, some of the identified photoproducts of bilirubin are also diazo-positive (38), and this latter method would also underestimate the photochemical events but demonstrably less than simply $\triangle$ O.D.460.

The results observed in Gunn rats also indicate a more effective wavelength at circa $488.0 \mathrm{~nm}$. It is clear that monochromatic light at $488.0 \mathrm{~nm}$ is at least as effective as monochromatic light at 457.9 $\mathrm{nm}$ and this would not have been predicted on the basis of the in
Table 3. In vivo decline in serum bilirubin

\begin{tabular}{|c|c|c|}
\hline \multirow[b]{2}{*}{ Wavelength (nm) } & \multicolumn{2}{|c|}{ Fractional remaining bilirubin ( \pm 1 S.D. } \\
\hline & $24 \mathrm{~h}$ & $48 \mathrm{~h}$ \\
\hline 457.9 & $0.815(0.0522)$ & $* \Gamma^{0.673(0.0391)}$ \\
\hline 476.5 & $* \Gamma^{0.856(0.0310)}$ & $L_{0.768(0.0310)}$ \\
\hline 488.0 & ${ }^{2} L 0.702(0.0457)$ & $L_{0.619}(0.0560)$ \\
\hline 514.5 & L $0.925(0.0538)$ & $L_{0.823(0.0596)}$ \\
\hline
\end{tabular}

${ }^{*} P<0.02$, unpaired Student $t$ test.

** $P<0.05$, unpaired Student $t$ test.

vitro absorption spectrum of albumin-bound bilirubin. Two general explanations, which are not exclusive, seem probable. (1) One may postulate the existence of other nonalbumin-bound bilirubin as a major chromophore(s) in vivo. The absorption spectrum of membrane-bound bilirubin with a maxima at $490 \mathrm{~nm}$ would fit this model nicely $(5,22)$, as would the postulated existence of a flocculant or a micro-gel diffusion of bilirubin in vivo (6), which also exhibit absorption maxima circa $490 \mathrm{~nm}$. (2) On the other hand, one may invoke the concept of the effectiveness spectrum described by Urbach (40). This is the net product of the action spectrum of the photochemical event and the spectrum of the light source (40). Non-icteric neonatal skin reflects more light at circa $460 \mathrm{~nm}$ than circa $490 \mathrm{~nm}(16)$, and both oxygenated and unoxygenated hemoglobin absorb better at circa $457.9 \mathrm{~nm}$ than circa $488.0 \mathrm{~nm}$ (41). In our in vivo model, the reflectance and scattering 
characteristics of the skin coupled with the competitive absorption of hemoglobin (as well as other potential unidentified modifiers) could reduce the availability of incident light at $457.9 \mathrm{~nm}$ relative to $488.0 \mathrm{~nm}$. The latter wavelength becomes more effective because it is the most "penetrating" to the layer(s) of skin where the photoalteration of bilirubin occurs. And the membrane-bound bilirubin absorbs light at $488.0 \mathrm{~nm}$ exceedingly well (22).

The demonstrated efficacy of light at $488.0 \mathrm{~nm}$ in vivo does not contradict previously published data. Rather, we suggest a different interpretation is possible. Because published data on the spectral output of "blue," "special blue," "cool white," and "daylight" fluorescent lights (39) indicate emission at $490 \mathrm{~nm}$ that parallels the emission at $460 \mathrm{~nm}$, the efficacy previously attributed to the $425-475 \mathrm{~nm}$ band may actually derive from the coincidental increased exposure to the longer wavelengths.

Our data highlight the complexity of the phenomena involved in the photochemistry of bilirubin and emphasize the need for caution in the interpretation or extrapolation of such data. That is, others have suggested that the in vitro photochemical events are those of photolysis whereas the in vivo events are those of photoisomerization; however, our data can neither support nor deny this. Although the action spectra may be identical and suggest that the mechanisms are also identical, the coincidental identity does not necessarily define that identity.

We believe our data provide additional evidence to supplement the work of Vogl (42) and Kapoor (22) in defining the site of in vivo bilirubin photoreactivity. The future design of light sources for phototherapy must be predicated on such information as well as a further clarification of dose-response or dose-time relationships if we are to maximize effect and minimize side-effect.

\section{ADDENDUM}

Since the preparation of this manuscript, Sbrana, et al. (34) have confirmed our earlier in vitro observations.

\section{REFERENCES AND NOTES}

1. Ballowitz, L., Geutler, G., Krochmann, J., Pannitschka, R., Roemer, G., and Roemer, I.: Phototherapy in Gunn rats. Biol. Neonate, 31: 229 (1977).

2. Blondheim, S. H., Lathrop, D., and Zambriskie, J.: The effect of light on the absorption spectrum of jaundiced serum. J. Lab. Clin. Med., 60: 31 (1962).

3. Bradley, M. O., Erickson, L. C., and Kohn, K. W.: Non-enzymatic DNA strand breaks induced in mammalian cells by fluorescent light. Biochem. Biophys. Acta, 520: 11 (1978).

4. Bradley, M. O. and Sharkeys, N. A.: Mutagenicity and toxicity of visible fluorescent light to cultured mammalian cells. Nature(London), 226: 724 (1977).

5. Broderson, R.: Bilirubin solubility and interaction with albumin and phospholipid. J. Biol. Chem. 254: 2364 (1979)

6. Broderson, R. and Theilgaard, J.: Bilirubin colloid formation in neutral aqueous solution. Scand. J. Clin. Lab. Invest., 24: 395 (1969).

7. Davies, R. E. and Keohane, S. J.: Some aspects of the photochemistry of bilirubin. Boll. Chimicofarm., 109: 589 (1970).

8. Ente, G., Lanning, E. W., Cukor, P., and Klein, R. M.: Chemical variables and new lamps in phototherapy. Pediatr. Res., 6: 246 (1972).

9. Forbes, P. D.: Influence of long wave UV on photocarcinogenesis. Abst. Am. Soc. Photobiol., 136 (1973).

10. Glauser, S. C., Lombard, S. A., Glauser, E. M., and Sisson, T. R. C.: Action spectrum for the photodestruction of bilirubin. Proc. Soc. Exp. Biol. Med., 136: 518 (1971).

11. Goldberg, S., Kendall, S., and Sisson, T. R. C.: Photodecomposition of bilirubin in vivo. Clin. Res., 18: 692 (1970).

12. Goyanes-Villaescusa, V. J., Urgarte, M., and Vasquez, A.: Sister chromatid exchange in babies treated by phototherapy. Lancet, 2: 1084 (1977).
13. Gray, C. H., Kulcycka, A., and Nicholson, D. C.: The photodecomposition of bilirubin and other bile pigments. J. Chem. Soc. Perkin Trans. I: 288 (1972).

14. Gutcher, G. R., Hwang, Y. S., Yen, W. M., and Odell, G. B.: The laserdetermined in vitro action spectrum of bilirubin. Pediatr. Res., 13: 296 (1979), (Abstract).

15. Gutcher, G. R., Yen, W. B., Luedtke, L., and Odell, G. B.: The laser-determined in vivo action spectrum of bilirubin. Pediatr. Res., 15: 662 (1981), (Abstract).

16. Hannemann, R. E., De Witt, D. P., and Wiechet, J. F.: Neonatal serum bilirubin from skin reflectance. Pediatr. Res., 12: 207 (1978).

17. Hewitt, J. R., Klein, R. M., and Lucey, J. F.: Photodegradation of serum bilirubin in the Gunn rat. Biol. Neonate, 21: 112 (1972).

18. Hsie, A. W., Li, A. P., and Machanoff, R.: A fluence response study of lethality and mutagenicity of white, black, and blue fluorescent light sunlamp and sunlight irradiation in chinese hamster ovary cells. Mutat. Res., 45: 333 (1977).

19. Jagger, J.: Phototechnology and Biological Experimentation in The Science of Photobiology. (Ed. Smith, K. C.). Plenum Press, New York, 1977, p. 25.

20. Jagger, J. Introduction to research in Uitraviolet Photobiology. (Prentice-Hall, Englewood Cliffs, N. J. 1967).

21. Jostes, R. E., Dewey, W. C., and Hopwood, L. E.: Mutagenesis by fluorescent light in mammalian cell cultures. Mutat. Res., 42: 139 (1977).

22. Kapoor, C. L., Krishna Murti, C. R., and Bajpai, P. C.: Uptake and release of bilirubin by skin. Biochem. J., 136: 35 (1973).

23. Kennedy, A. R., Ritter, M. A., and Little, J. B.: Fluorescent light induces malignant transformation in mouse embryo cell cultures. Science, 207: 1209 (1980).

24. Lee, K. And Gartner, L. M.: Spectrophotometric characteristics of bilirubin. Pediatr. Res., 10: 782 (1976).

25. Lightner, D. A. and $\mathrm{Cu}, \mathrm{A}$.: Wavelength dependence of bilirubin photoreactivity. Life Sci., 20: 723 (1977)

26. Lightner, D. A., Wooldridge, T. A., Rogers, S. L., and Norris, R. D.: Action spectra for bilirubin photodisappearance. Experientia, 36: 380 (1980).

27. Lilien, L. D., Voora, S., Srinivasan, G., and Pildes, R. S.: Blue light vs. white light on bilirubin photodegradation in vitro. Pediatr. Res., 15: 669 (1981), (Abstract).

28. Malloy, H. T. and Evelyn, K. A.: The determination of bilirubin with the photoelectric colorimeter. J. Biol. Chem. 119: 481 (1937).

29. Ostrow, J. D.: Photocatabolism of labelled bilirubin in the congenitally jaundiced (Gunn) rat. J. Clin. Invest. 50: 707 (1971).

30. Ostrow, J. D.: Mechanisms of bilirubin photodegradation. Semin. Hemat., 9: 113 (1972).

31. Ostrow, J. D. and Branham, R. V.: Photodecomposition of bilirubin and biliverdin in vitro. Gastroenterology, 58: 15 (1970).

32. Puck, T. T and Kao, F, T. Genetics of somatic mammalian cells. V. Treatment with 5-bromodeoxy uridine and visible light for isolation of nutritionally deficient mutants. Proc. Natl. Acad. Sci. (U.S.A.), 58: 1227 (1967).

33. Raethel, H. A.: Wavelengths of light producing photodecomposition of bilirubin in serum from a neonate with hyperbilirubinemia. J. Pediatr. 87: 110 (1975).

34. Sbrana, G., Migliorini, M. D., Vecchi, C., and Donzelli, G. P.: Laser photolysis of bilirubin. Pediatr. Res. 15: 1517 (1981).

35. Sideris, E. G., Papageorgiou, G. C., Charalampous, S. C., and Vitsa, E. M.: A spectrum response study on single strand DNA breaks, sister chromatid exchanges, and lethality induced by phototherapy lights. Pediatr. Res., 15: 1019 (1981).

36. Sisson, T. R., Kendall, N., Shaw, E. and Kechavarz-Oliai, L.: Phototherapy of jaundice in the newborn infant. J. Pediatr., 81: 35 (1972).

37. Speck, W. T., and Rosenkranz, H. S.: Intracellular DNA-modifying activity of high intensity light. Pediatr. Res., 10: 553 (1976).

38. Stoll, M. S., Zenone, E. A., Ostrow, J. D., and Zarembo, E.: Preparation and properties of bilirubin photoisomers. Biochem. J., 183: 139 (1979).

39. Thorington, L., Cunningham, L., and Parascandola, J.: The illuminant in the prevention and phototherapy of hyperbilirubinemia. Illum. Engin., 66: 240 (1971).

40. Urbach, F. (ed.).: The Biologic Effects of Ultraviolet Radiation, (Pergamon Press, New York, 1969).

41. van Assendelft, O. W.: Spectrophotometry of Hemoglobin Derivatives. (Charles C Thomas Publisher, Springfield, Illinois, U.S.A. 1970)

42. Vogl, T. P.: Phototherapy of neonatal hyperbilirubinemia: bilirubin in unexposed areas of the skin. J. Pediatr., 85: 707 (1974).

43. Requests for reprints should be addressed to: Dr, Gary R. Gutcher, Rm H4/474, Center for Health Sciences, University of Wisconsin, Madison, Wisconsin 53792.

44. Received for publication February 8, 1982

45. Accepted for publication June 16, 1982. 